\title{
Coating of Mineral Acids with Niobic Solid Acid for Preparing Furfural from Nut Shell of Camellia oleifera Abel
}

\author{
Lisong Hu, Menghao Du, Jingping Zhang \\ Research Institute of Subtropical Forestry Chinese Academy of Forestry, Fuyang, China \\ Email: lisohu@hotmail.com
}

How to cite this paper: Hu, L.S., Du, M.H. and Zhang, J.P. (2016) Coating of Mineral Acids with Niobic Solid Acid for Preparing Furfural from Nut Shell of Camellia oleifera Abel. Open Journal of Forestry, 6, 486-497. http://dx.doi.org/10.4236/ojf.2016.65037

Received: October 9, 2016

Accepted: October 24, 2016

Published: October 27, 2016

Copyright (c) 2016 by authors and Scientific Research Publishing Inc. This work is licensed under the Creative Commons Attribution International License (CC BY 4.0).

http://creativecommons.org/licenses/by/4.0/

\begin{abstract}
Nut shell of Camellia oleifera Abel which has large scale of plantation in mountainous region of southern China is abundant renewable resource. The nut shell is suitable for preparation of furfural, as the content of which is as much as $16 \%$ (based the dried nut shell). In early time, mineral acids were employed as typically catalyst for preparing of furfural from the nut shells. These mineral acids could pollute water and corrode equipment. In this paper we used various mineral acids coating with niobic acid as catalysts to investigate reactions for preparation of furfural. Among these catalysts, the catalyst of sulfuric acid coating with niobic acid was found to be very effective, which had higher hammett acidity and better effect of hydrolysis of the nut shells; The catalysts of sulfuric acid coating with niobic acid was characterized, and the conditions of preparation of the catalyst were investigated. The optimum conditions were: sulfuric acid as coating acid, the concentration of sulfuric $1.1 \mathrm{~mol} / \mathrm{L}$, impregnation time $8 \mathrm{~h}$, calcination time $8 \mathrm{~h}$ and calcination temperature $450^{\circ} \mathrm{C}$. Then hydrolysis of the nut shells was explored, the optimum conditions were as follows: dose of catalyst $20 \%$, ratio of solid to liquid $1: 15$, reaction temperature $100^{\circ} \mathrm{C}$, reaction time $4 \mathrm{~h}$; Under this condition, the yield of furfural was $8.7 \%$.
\end{abstract}

\section{Keywords}

Furfural, Niobic Acid, Nut Shell of Camellia oleifera Abel, Hydroliysis

\section{Introduction}

Camellia oil also known as tea seed oil is pressed or extracted by solvents (e.g. hexane) from the fruits of Camellia oleifera Abel, which was widely distributed in mountainous region of southern China, and has been used as cooking oil for centuries (Sahari, Ataii, 
\& Hamedi, 2004; Shi et al., 2010). Tea seed oil as well as known as eastern olive oil comprises oleic acid, linoleic acid, a-linolenic acid, stearic acid, vitamin E, flavonoids, sterol and polyphenols, and the ingredients of which are very similar to the compositions of olive oil (Zhang et al., 2008; Zhang, Xue, Zhong, Xu, \& Zhu, 2014). Besides, tea seed oil is also applied in pharmaceutics (Wei et al., 2016; Zhang, Wang, Wu, Xu, \& Chen, 2010; Zhou et al., 2014; Zong et al., 2015), cosmetics (Jadoon et al., 2015) and agriculture (Ye, Li, \& Fang, 2015). Tea seed oil is very popular and arouse extensively interests all over the world. Governments and researchers made strategy to enlarge the scale of plantation and cultivation of the Camellia oleifera Abel; Many refineries were set up for producing tea seed oil in mountainous area.

As plantation and production of tea seed oil increasing, the nut shell of the Camellia oleifera Abel which is 60 wt.\% as much as the whole fresh fruit need to be studied. The nut shell contains lignin, cellulose, hemicellulose (Zhang et al., 2009), saponin (Zong, et al., 2015), protein and starches. In early time, the nut shell was discarded as forestry waste or fermented as feed stuff (Woznica, Nalewaja, Messersmith, \& Milkowski, 2003). However, these utilizations in some degree were waste of natural resource. Moreover, utilization of renewable, environmental-friendly raw materials is very popular all over the world. Nowadays many researchers were focused on use agricultural plant and forest industry by-products (Karinen, Vilonen, \& Niemelä, 2011). The nut shell of Camellia oleifera Abel was applied for fish removing agent, xylosic alcohol, furfural, tannin, active charcoal and lignin derivatives (Yang et al., 2015; Zhang, et al., 2009; Zong, et al., 2015).

Furfural (see Figure 1) is a common industry solvent and a platform chemical for the production of fine chemicals, resins and biofuels components (Climent, Corma, \& Iborra, 2011; Xing et al., 2010). Furfural usually was prepared by corn, oats, and sawdust, nut shell and formed by the acid-catalyzed dehydration of xylose (the most abundant pentose present in the hemicellulose component of lignocellulose biomass), and it is produced industrially through processes that commonly use mineral acids as catalysts (e.g. $\mathrm{H}_{2} \mathrm{SO}_{4}$ ) (Russo et al., 2013). Niobic acid $\left(\mathrm{Nb}_{2} \mathrm{O}_{5} \cdot \mathrm{nH}_{2} \mathrm{O}(\mathrm{NBO})\right.$ ) is considered one of the most promising water-tolerant solid acid catalyst, and it was applied in esterification, dehydration, hydroxylation and alkylation (Carlini et al., 1999; Nakajima et al., 2011; Nowak \& Ziolek, 1999). Niobic acid has been exploited in several reactions of biomass transformation as dehydration of pentose and hexoses to obtain platform compounds such as furfural and 5-hydroxymethyl furfural, respectively (Carniti, Gervasini, Biella, \& Auroux, 2006; Yang, Liu, Bai, \& Du, 2011). However, it is reported that the acidity of solid acid was not high and led to low yield and conversion of

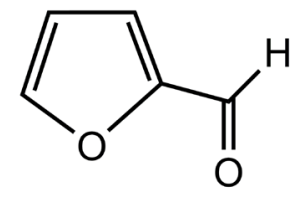

Furfural

Figure 1. The chemical structure of furfural. 
products (Wei, Chen, Zhang, \& Zhan, 2004).

The nut shell of Camellia oleifera Abel theoretically could produce $16 \%$ yield (based dried nut shell of Camellia oleifera Abel) of furfural, which was very suitable for preparation of the furfural. However, due to the components in nut shell of Camellia oleifera Abel is very complicated, the study of the preparation of furfural from the nut shell was rarely reported. In early 1970s, furfural prepared from nut shells catalyzed by mineral acids (e.g. sulfuric acid) could have 5\% - $8 \%$ yield. In this paper, we used the catalysts of niobic acid coating with mineral acids to enforce the acidity. As for today, there has been no report on the direct use of niobic acid to hydrolysis of nut shells of Camellia oleifera Abel for preparation of furfural. The objective of this paper is to report on a novel catalyst to prepare furfural from nut shell of Camellia oleifera Abel.

\section{Experimental}

\subsection{Materials}

The nut shells were obtained from Zhejiang kangneng food Ltd., co. and dried at $105^{\circ} \mathrm{C}$ for $8 \mathrm{~h}$ in oven then smashed to $60-80$ mesh of powder for use. Concentrated sulfuric acid, furfural and toluene were purchased from Aladdin Industrial Inc. and used without further purification. Niobic acid was purchased in Jiujiang nonferrous metal Ltd., co. The other chemicals were purchased from state medicine company without further purification.

\subsection{Characterization}

Spectra of Fourier Transform Infrared Spectrometer (FTIR) were recorded on a nicolet Is10 by an attenuated total reflectance method (Tarantilis, Troianou, Pappas, Kotseridis, \& Polissiou, 2008) using KBr pellets of the solid.

The acidity determination of the catalyst samples was performed by ionic-exchange procedure followed by titration of the acidity released from the solid acid in aqueous solution by employing a Metrohm 736 GP Titrino. The weighted amount of dry sample was put in water under vigorous stirring in the presence of $\mathrm{KCl}$ (ca.0.2 M) for $2 \mathrm{~h}$; the resultant suspension was titrated by $\mathrm{NaOH}(0.1 \mathrm{M})$. The acidity of the surface was determined by following the procedure described by (Curthoys, 1980) with visible indicators as recommended by drushel and sommers and arylmethanol indicators as introduced by Hischler. Samples of the solid acid were transferred in a dry box to each of 25 reweighed screwcap vials of approximately $15 \mathrm{~mL}$. The solid was covered with dry benzene. Out of the dry box increasing aliquots of $0.04 \mathrm{M}$ n-butylamine in benzene were added to the vials. The samples were equilibrated with shaking overnight and small amounts of each suspension transferred to small vials and tested with a few drops of $0.1 \%$ solution of each indicator in benzene. The vials in which the appropriate color change occurred were noted, and the acidity was determined from the number of millimoles of n-butylamine which had to be added before the appropriate color change occurred. In this titration procedure, the influence of moisture and overlap of the indicators were reduced minimum. 


\subsection{Standard Curve Drawing of Furfural}

To determine the yield of furfural, the furfural standard cure was set up. The furfural was purchased from Aladdin Industrial Inc. and distilled to collect the $106^{\circ} \mathrm{C}-108^{\circ} \mathrm{C}$ fractions as standard. The ultraviolet spectrophotometric (UV) was performed on Shimadazu UV-2550 in double bean model. Dissolved the standard in distilled water to 1 $5 \mu \mathrm{L} / \mathrm{L}$ as the furfural standard solutions and carried out at $276.9 \mathrm{~nm}$. The standard cure and Unitary Lin-ear Regression Equation as follows: $\mathrm{Y}=0.18667 \mathrm{X}+0.16499, \mathrm{R}^{2}=$ 0.99986.

\subsection{Preparation of Niobic Acid}

The preparation of niobic acid was carried out using a similar procedure as previous reported (Ushikubo, Iizuka, Hattori, \& Tanabe, 1993). Niobic acid dissolved in oxalic acid solution was added, then add $6 \mathrm{~N} \mathrm{KOH}$ solution added to precipitates of niobium hydroxide. The precipitates washed with pure water 5 times at room temperature, then washed 5 times. Treated with boiling $6 \mathrm{~N} \mathrm{HCl}$ solution at room temperature followed by washing with pure water 4 times at room temperature, and calcined in muffle furnace.

\subsection{Catalytic Tests}

Batch experiments were performed under nitrogen atmosphere in closed tubular glass micro-reactors (30 $\mathrm{mL}$ capacity) equipped with a PTFE-coated magnetic stirring bar. In a typical procedure, the reactor was loaded with $1 \mathrm{~g}$ nut shells in $10 \mathrm{~mL}$ water and certain amount niobic acid at same temperature for hours, then examined the content of furfural according to the standard procure. And the yield of furfural calculated as follows:

$$
\text { Yeild }=\frac{\text { Obtained furfural }}{\text { weight of nut shell }} * 100 \%
$$

\section{Results and Discussion}

\subsection{Preparation and Characterization of Niobic Acids}

Niobic acid made from the niobic oxide showed very good water-tolerant characteristics and good performance in canalization of many reactions in water (Guo et al., 2003; Lachenmeier, Kroener, Musshoff, \& Madea, 2004). In this paper, various mineral acids coating with niobic acid were prepared with different preparation conditions such as impregnation time, calcination temperature and calcination time and different acids (e.g. sulfuric acid, phosphoric acid, hydrochloric acid and nitric acid).

Acidity is one of the most important character for the catalysts (Lercher, Gründling, \& Eder-Mirth, 1996). N-butyl amine titration method was employed for determining the acidity of catalysts (Luz et al., 2013). As shown in Table 1, the niobic acid coating with sulfuric acid, its acidity was -14.52 of hammette acidity, when the other mineral acids coating with niobic acid, their hammett acidity were $-12.44,-13.16$ and -12.70 . Among them, the sulfuric acid coating with niobic acid had the highest acidity. More- 
Table 1. Different hammeet acidity of mineral acids coating with niobic acid.

\begin{tabular}{cc}
\hline Mineral acids & Hammeet acidity $\left(\mathrm{H}_{0}\right)$ \\
\hline Phosphoric acid & -12.44 \\
Sulfuric acid & -14.52 \\
Hydrochloric acid & -13.16 \\
Nitrate acid & -12.70 \\
\hline
\end{tabular}

Notes: the contents of mineral acids for impregnation $0.8 \mathrm{~mol} / \mathrm{L}$, impregnation time $4 \mathrm{~h}$; calcination temperature $300^{\circ} \mathrm{C}$, calcination time $4 \mathrm{~h}$.

over, when the sulfuric acid coating with niobic acid were employed to hydrolysis of nut shell of Camellia oleifera Abel at the experimental conditions (reaction temperature $100^{\circ} \mathrm{C}$, water as solvent, etc.), the yield of furfural was $7.1 \%$, which was higher than other mineral acids coating with niobic acids (see Figure 2). Therefore, in our research, sulfuric acid coating with niobic acid was selected as the catalyst to study the preparation of furfur from the nut shells of Camellia oleifera Abel.

As shown in Figure 3, the three FTIR spectra showed absorption peaks at around the $1420 \mathrm{~cm}^{-1}$ and $1950 \mathrm{~cm}^{-1}$ were corresponding to the $\mathrm{Nb}-\mathrm{O}$ vibration. When the nitrite acid and sulfuric acid coating with niobic acid, the peak became broad and showed new absorption peak at $1100 \mathrm{~cm}^{-1}$ and $1530 \mathrm{~cm}^{-1}$. These peaks were characterized peaks for nitrite acid and sulfuric acid respectively. Due to niobic acid had a low acidity in some reactions (Nowak \& Ziolek, 1999), we modified the niobic acid by coating mineral acids to enforce the acidity, the results (see Table 1 ) showed that the acidity of the modified niobic remarkable increased. Compared to modified niobic acids (e.g. coating with hydrochloric acid and nitric acid), the sulfuric acid coating with niobic acid had better acidity and higher yield of furfural at the same experimental conditions. Therefore, in this paper, we applied sulfuric acid coating with niobic acids to study on the hydrolysis of nut shell of Camellia oleifera Abel for preparation of furfural.

As shown in Figure 4, when the concentrations of sulfuric acid were lower than 1.1 $\mathrm{mol} / \mathrm{L}$, as the concentration of sulfuric acid rising, the yields of furfural from Camellia oleifera Abel were increasing. When the concentration of sulfuric acid was $1.1 \mathrm{~mol} / \mathrm{L}$, the yield of furfural was maximum. At this point, the yield of furfural was $3.9 \%$. Contrary to the sulfuric acid concentration continued to increase, the yields of furfural were decease. This decrease of the yield of furfural could be attribute to high concentration of sulfuric acid covering the surface of niobic acid, so that sulfuric acids were difficult to penetrate the pore of solid acids result in sulfuric acid were poor distribute on the surface of the niobic acid. However, the concentration of sulfuric is low, the sulfuric were insufficient to distribute on the surface of niobic acid.

The impregnation process is a period for the mineral acid adequately adsorbing on the niobic acid particles. As shown in Figure 5, the yield of furfural was maximum at $8 \mathrm{~h}$. the impregnation time was less than $8 \mathrm{~h}$, the sulfate anion had less chance to interact with niobic acid led to acidity of the combine mixture became weaker. The impregnation 


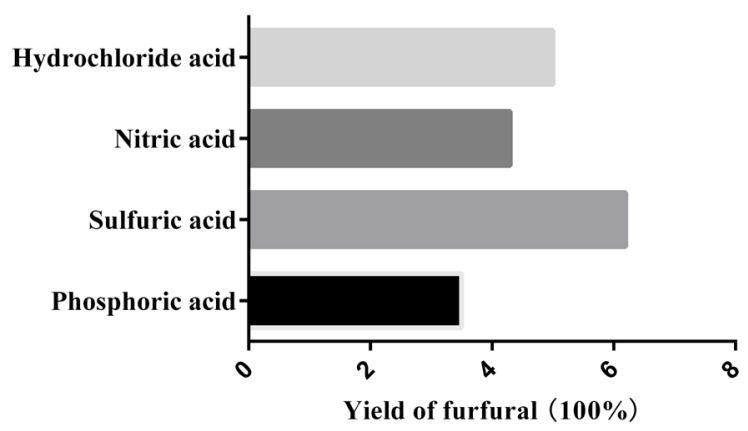

Figure 2. Yields of furfural from the nut shell of Camellia olieferal Abel with mineral acids coating with niobic acid. Notes: concentration of impregnated acids $0.8 \mathrm{~mol} / \mathrm{L}$, impregnation temperature $300^{\circ} \mathrm{C}$, impregnation time $4 \mathrm{~h}$; The conditions of hydrolysis: dose of catalyst $15 \mathrm{wt} \%$, ratio of solid to liquid $=1: 10(\mathrm{~g} / \mathrm{ml})$, reaction temperature $100^{\circ} \mathrm{C}$, reaction time $2 \mathrm{~h}$.

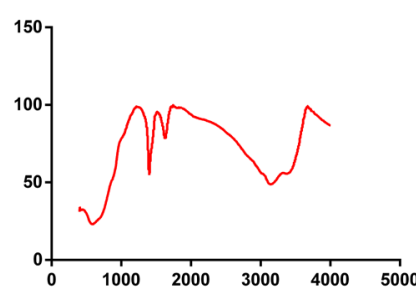

Niobic acid

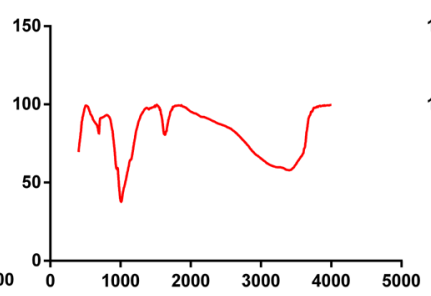

Sulfuric acid coatin with niobic acid

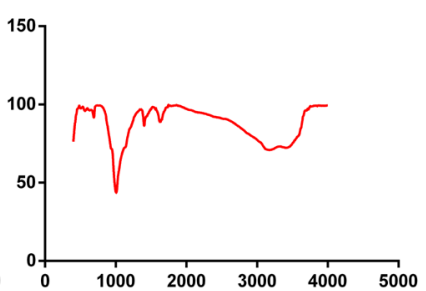

Nitric acid coating with niobic acid

Figure 3. The spectra of FTIR of niobic acid and mineral acids coating with niobic acid. Notes: concentration of impregnated acids $0.8 \mathrm{~mol} / \mathrm{L}$, impregnation temperature $300^{\circ} \mathrm{C}$, impregnation time $4 \mathrm{~h}$; The conditions of hydrolysis: reaction temperature $100^{\circ} \mathrm{C}$, ratio of solid to liquid $=1: 10$ $(\mathrm{g} / \mathrm{ml})$, dose of catalyst $15 \mathrm{wt} \%$, reaction time $2 \mathrm{~h}$.

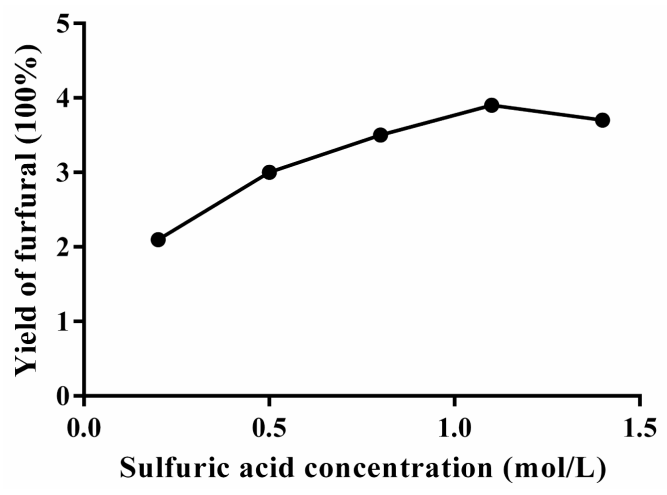

Figure 4. Effects of concentration of sulfuric acid on yields of furfural prepared from nut shell of camellia oleifera Abel. Note: impregnation time $4 \mathrm{~h}$, calcination temperature $300^{\circ} \mathrm{C}$, calcination time $4 \mathrm{~h}$; The conditions of hydrolysis: dose of catalyst $15 \mathrm{wt} \%$, ratio of solid to liquid $=1: 10$ $(\mathrm{g} / \mathrm{ml})$, reaction temperature $100^{\circ} \mathrm{C}$, reaction time $2 \mathrm{~h}$.

time were more than $8 \mathrm{~h}$, the surface of the solid acids covering more sulfate anion and hindered other sulfate anion entering the pore of the niobic solid acid.

The calcination temperature for preparation of solid acid is one of the most key factors for the acidity of the catalysts. When calcination temperature is too high, the acid 


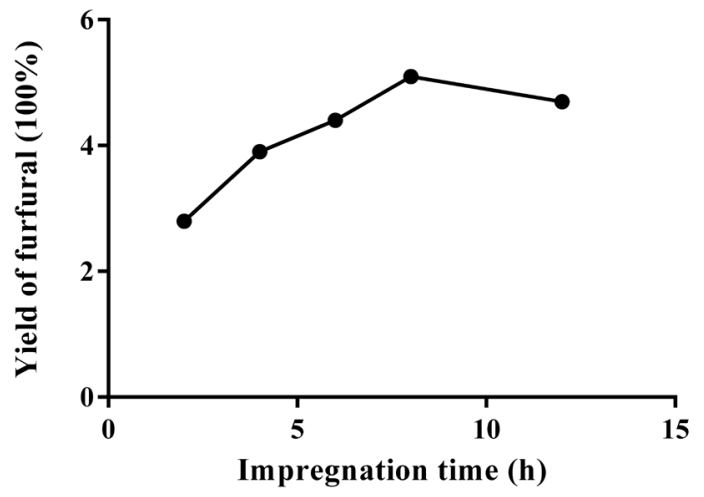

Figure 5. Effects of impregnation time on yields of furfural prepared from nut shell of camellia oleifera Abel of sulfuric acid on niobic acid. Notes: The reaction conditions: concentration of sulfuric acid $1.1 \mathrm{~mol} / \mathrm{L}$, calcination temperature $300^{\circ} \mathrm{C}$, calcination time $4 \mathrm{~h}$; Conditions of hydrolysis: dose of catalyst $15 \mathrm{wt} \%$, ratio of solid to liquid $=1: 10(\mathrm{~g} / \mathrm{ml})$, reaction temperature $100^{\circ} \mathrm{C}$,reaction time $2 \mathrm{~h}$.

center would minimize the number of acid center in solid acid. On the contrary, the low calcination temperature would affect the functional group binding which also led to the acidity of solid acids decreasing. As shown in Figure 6, sulfuric acid coating with niobic acid at $450^{\circ} \mathrm{C}$, the yield of furfural was optimum.

At other reaction conditions not changed, the time of calcination affect the hydrolysis for production of furfural from nut shells of Camellia oleifera Abel; If the calcination time is too short, the acid center seemed weak there. In contrary to the long time of calcination, the acid center would be broken. As the Figure 7 shown calcination time as 8 $\mathrm{h}$, the yields of the furfural is optimum. And calcination temperature showed the similar affect results and $450^{\circ} \mathrm{C}$ was better for the calcination of the sulfuric acid coating with niobic acid.

According to the single factor experiments, the optimum condition for preparation of mineral acid coating with niobic acid were as follows: the sulfuric acid as coating acid, the concertation of sulfuric $1.1 \mathrm{~mol} / \mathrm{L}$, impregnation time $8 \mathrm{~h}$, calcination time $8 \mathrm{~h}$ and calcination temperature $450^{\circ} \mathrm{C}$. The catalyst of sulfuric coating with niobic acid prepared at optimum conditions was named catalyst A.

\subsection{Hydrolysis of Nut Shell of Camellia oleifera Abel to Preparation of Furfural}

Typically, production of furfural is prepared through hydrolysis of agriculture and forestry waste, corn cob etc. with mineral acid (e.g. Sulfuric acid, hydrochloride acid). In this paper, we selected sulfuric acid coating with niobic acid to prepare furfural. And compared to the sulfuric acid, the yields of furfural were a little bit lower than sulfuric acid, and much higher than niobic acid (as shown in Table 2). From the environmental, renewable and sustainable point of view, sulfuric acid coating with niobic acid is a promising heterocatalysts for the hydration of hemicellulose contained materials.

In this paper, we applied the sulfuric acid coating with niobic acid, which is the optimum catalyst selected via above factors of reactions named the catalyst $\mathrm{A}$ to 


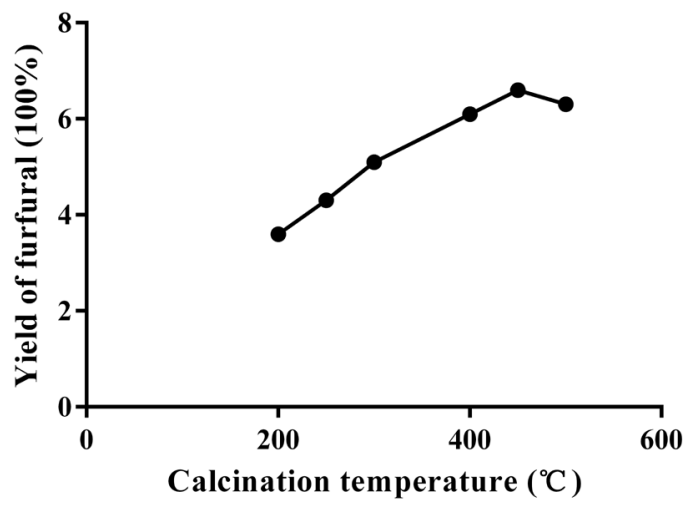

Figure 6. Effects of calcination temperature on yields of furfural preparation from nut shells $\mathrm{Ca}$ mellia oleifera Abel. Notes: The reaction conditions: concentration of sulfuric acid $1.1 \mathrm{~mol} / \mathrm{L}$, impregnation time $8 \mathrm{~h}$, calcination time $4 \mathrm{~h}$; hydrolysis of dose of catalyst $15 \mathrm{wt} \%$, ratio of solid to liquid $=1: 10(\mathrm{~g} / \mathrm{ml})$, reaction temperature $100^{\circ} \mathrm{C}$, reaction time $2 \mathrm{~h}$.

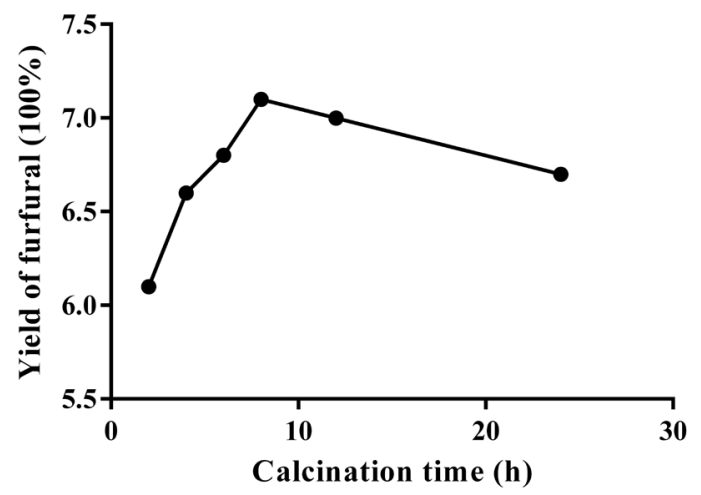

Figure 7. Effects of calcination time on yields of furfur preparation from nut shells camellia oleifera Abel with sulfuric acid coating with niobic acid. Notes: The reaction conditions: concentration of sulfuric acid $1.1 \mathrm{~mol} / \mathrm{L}$, impregnation time $8 \mathrm{~h}$, calcination temperature $450^{\circ} \mathrm{C}$; Conditions of hydrolysis: dose of catalyst $15 \mathrm{wt} \%$, ratio of solid to liquid $=1: 10(\mathrm{~g} / \mathrm{ml})$, reaction temperature $100^{\circ} \mathrm{C}$, reaction time $2 \mathrm{~h}$.

Table 2. Yields of furfural with different catalysts.

\begin{tabular}{cc}
\hline Catalysts & Yields of furfural \\
\hline Concentrated sulfuric acid & $8.1 \%$ \\
Niobic acid & $4.2 \%$ \\
Catalyst A & $7.1 \%$ \\
\hline
\end{tabular}

Notes: conditions of reaction were as follows: dose of catalyst $15 \mathrm{wt} \%$, ratio of solid to liquid $=1: 10(\mathrm{~g} / \mathrm{ml})$, reaction temperature $100^{\circ} \mathrm{C}$, reaction time $2 \mathrm{~h}$.

investigate the reactions of hydrolysis of nut shell of Camellia oleifera able to prepare furfural. And the results showed that the dose of sulfuric acid, ratio of solid to liquid, reaction temperature and reaction time (see Figure 8) affected the yields of the furfural. When the dose of the catalyst was $20 \mathrm{wt} \%$ (base of the weight of nut shells of Camellia oleifera able), the yield of furfural was $7.5 \%$. When the dose of catalysts was $25 \%$, the 
Dose of the catalyst

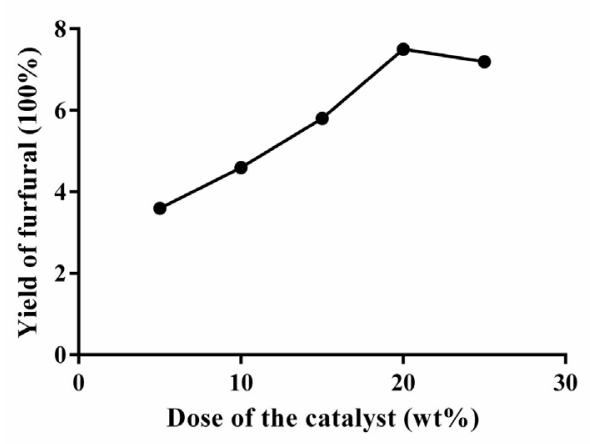

(a)

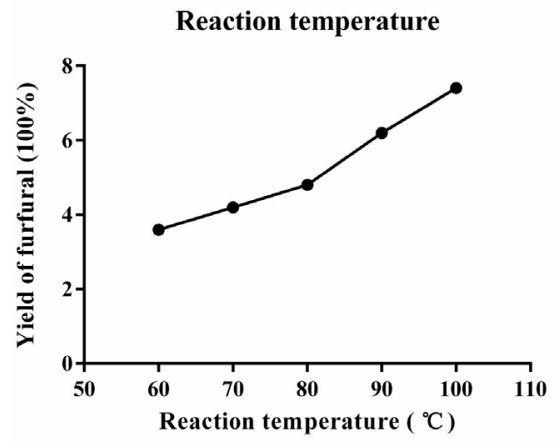

(c) ratio of solid to liquid

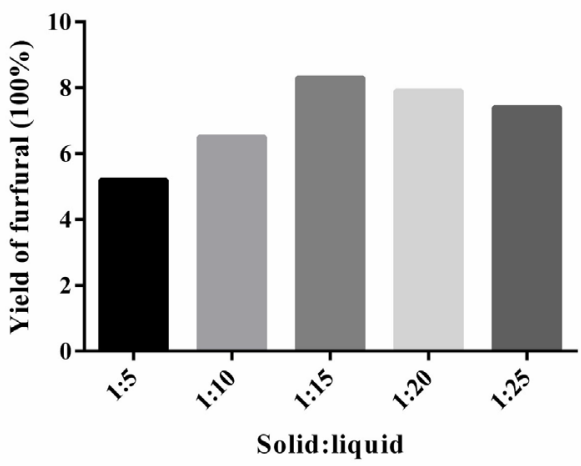

(b)

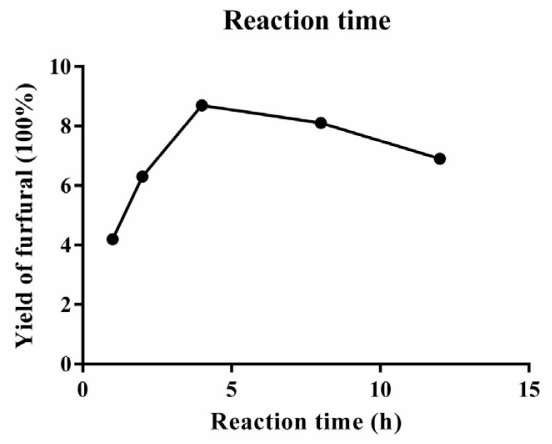

(d)

Figure 8. Effects of experimental factors on the yields of furfural with the catalyst A. Notes: (a) ratio of solid to liquid $=1: 10(\mathrm{~g} / \mathrm{ml})$, reaction temperature $100^{\circ} \mathrm{C}$, reaction time $2 \mathrm{~h}$; (b) dose of the catalyst A $20 \%$, ratio of solid to liquid $=1: 10(\mathrm{~g} / \mathrm{ml})$, reaction temperature $100^{\circ} \mathrm{C}$, reaction time $2 \mathrm{~h}$; (c) dose of the catalyst A $20 \%$, ratio of solid to liquid $=1: 10(\mathrm{~g} / \mathrm{ml})$, reaction time $2 \mathrm{~h}$; (d) dose of the catalyst A $20 \%$, ratio of solid to liquid $=1: 10(\mathrm{~g} / \mathrm{ml})$, reaction temperature $100^{\circ} \mathrm{C}$.

yields of furfural was lower than the yields of which dose of $20 \%$. The reason was that as the dose of the catalysts increasing, the product of furfural would conversion to other chemicals (see Figure 8(a)). The solvent used in our experiments were water which is friendly and renewable resource on the Earth. The ratio of nut shell to liquid were carried out at $80^{\circ} \mathrm{C}, 20 \%$ of the catalyst (based the weight of the nut shell) for $2 \mathrm{~h}$. The results (see Figure $8(\mathrm{~b})$ ) showed that the ratio of solid to liquid was $1: 15$, the yield of the furfural from the Camellia oleifera Abel was $8.2 \%$. Reaction temperature which could accelerate the speed of reactions and saving reaction time is a key for factor for the most of reactions. As shown in Figure $8(\mathrm{c})$, reaction time was $100^{\circ} \mathrm{C}$, the yields were very good. However, from the trend of Figure $8(c)$, the reaction temperature was the higher the better. As we known, the boiling water is $100^{\circ} \mathrm{C}$ at atmospheric pressure, once, the temperature is more than $100^{\circ} \mathrm{C}$, we need to use pressure equipment which is waste of energy and steels for the reactions. As shown in Figure 8(d), the yield of furfural was $8.5 \%$ at $4 \mathrm{~h}$ of temperature time. When reaction time was more than $4 \mathrm{~h}$, side reaction would occur, yield of furfural would decrease. 


\section{Conclusions}

In this work, we have shown that sulfuric acid coating with niobic acid is effective for the preparation of furfural from the nut shell of Camellia oleifera Abel. Various mineral acids coating with niobic acids were prepared. Among them, the sulfuric acid coating with niobic acids were found to be very effective catalysts with higher hammett acidity and better effect of hydrolysis of nut shell of Camellia oleifera Abel; the catalysts of sulfuric acid coating with niobic acid was characterized, and the conditions of preparation of the catalyst were investigated. This kind of catalyst was friendly and no pollution to environment and reaction equipment. The effects of hydrolysis conditions such as dose of catalyst, ratio of solid to liquid, reaction temperature and reaction time were carried out through single factor's reactions. The results showed that the catalysts were more effective than niobic acid.

Our future work will focus on development of the recycle system of catalysts, which catalysts will reactive and explore the toxic factors. These are the key factors to obtain successful catalytic process in the preparation of furfural from nut shells of Camellia furfural oleifera Abel.

\section{Acknowledgements}

The authors gratefully acknowledge Dongbing Zhang for providing us lab assistance. This work was supported by the project of Science and Technology Department of Zhejiang Province, China (2014C32122) and China Ministry of Science and Technology (2016 YFD0600803).

\section{References}

Carlini, C., Giuttari, M., Galletti, A. M. R., Sbrana, G., Armaroli, T., \& Busca, G. (1999). Selective Saccharides Dehydration to 5-Hydroxymethyl-2-Furaldehyde by Heterogeneous Niobium Catalysts. Applied Catalysis A: General, 183, 295-302. http://dx.doi.org/10.1016/S0926-860X(99)00064-2

Carniti, P., Gervasini, A., Biella, S., \& Auroux, A. (2006). Niobic Acid and Niobium Phosphate as Highly Acidic Viable Catalysts in Aqueous Medium: Fructose Dehydration Reaction. Catalysis Today, 118, 373-378. http://dx.doi.org/10.1016/j.cattod.2006.07.024

Climent, M. J., Corma, A., \& Iborra, S. (2011). Converting Carbohydrates to Bulk Chemicals and Fine Chemicals over Heterogeneous Catalysts. Green Chemistry, 13, 520-540.

http://dx.doi.org/10.1039/c0gc00639d

Curthoys, G. (1980). Acid-Site Distribution on Faujasite-Type Zeolites Determined by n-Butylamine Titration. 1. Comparison of the Use of Hammett and Arylmethanol Indicators on Zeolites X. Journal of Physical Chemistry, 84, 1358-1360. http://dx.doi.org/10.1021/j100448a014

Guo, X. J., Hou, W. H., Kong, Y., Lu, C. L., Yao, T. Y., \& Yan, Q. J. (2003). Synthesis of TitaniaPillared Layered Niobic Acid with a High Specific Surface Area by Using Sol-Intercalation Method. Chinese Journal of Inorganic Chemistry, 19, 273-277.

Jadoon, S., Karim, S., Asad, M. H. H. B., Akram, M. R., Kalsoom Khan, A., Malik, A. et al. (2015). Anti-Aging Potential of Phytoextract Loaded-Pharmaceutical Creams for Human Skin Cell Longetivity. Oxidative Medicine and Cellular Longevity, 2015, Article ID: 709628. http://dx.doi.org/10.1155/2015/709628 
Karinen, R., Vilonen, K., \& Niemelä, M. (2011). Biorefining: Heterogeneously Catalyzed Reactions of Carbohydrates for the Production of Furfural and Hydroxymethylfurfural. ChemSusChem, 4, 1002-1016. http://dx.doi.org/10.1002/cssc.201000375

Lachenmeier, D. W., Kroener, L., Musshoff, F., \& Madea, B. (2004). Determination of Cannabinoids in Hemp Food Products by Use of Headspace Solid-Phase Microextraction and Gas Chromatography-Mass Spectrometry. Analytical and Bioanalytical Chemistry, 378, 183-189. http://dx.doi.org/10.1007/s00216-003-2268-4

Lercher, J. A., Gründling, C., \& Eder-Mirth, G. (1996). Infrared Studies of the Surface Acidity of Oxides and Zeolites Using Adsorbed Probe Molecules. Catalysis Today, 27, 353-376. http://dx.doi.org/10.1016/0920-5861(95)00248-0

Luz, G. E., Lima, F. C. A., Neto, C. O. C., Paz, G. L., Silva, E. F. B., \& Barbosa, M. N. (2013). Determination of SBA-15 Acidity through n-Butyl Amine TPD: A Theoretical and Experimental Study. Journal of Materials Science, 48, 6885-6890.

http://dx.doi.org/10.1007/s10853-013-7492-5

Nakajima, K., Baba, Y., Noma, R., Kitano, M., N. Kondo, J., Hayashi, S., et al. (2011). $\mathrm{Nb}_{2} \mathrm{O}_{5} \cdot \mathrm{nH}_{2} \mathrm{O}$ as a Heterogeneous Catalyst with Water-Tolerant Lewis Acid Sites. Journal of the American Chemical Society, 133, 4224-4227. http://dx.doi.org/10.1021/ja110482r

Nowak, I., \& Ziolek, M. (1999). Niobium Compounds: Preparation, Characterization, and Application in Heterogeneous Catalysis. Chemical Reviews, 99, 3603-3624.

http://dx.doi.org/10.1021/cr9800208

Russo, P. A., Lima, S., Rebuttini, V., Pillinger, M., Willinger, M.-G., Pinna, N., et al. (2013). Microwave-Assisted Coating of Carbon Nanostructures with Titanium Dioxide for the Catalytic Dehydration of d-Xylose into Furfural. RSC Advances, 3, 2595-2603.

http://dx.doi.org/10.1039/c2ra22874b

Sahari, M. A., Ataii, D., \& Hamedi, M. (2004). Characteristics of Tea Seed Oil in Comparison with Sunflower and Olive Oils and Its Effect as a Natural Antioxidant. Journal of the American Oil Chemists' Society, 81, 585-588. http://dx.doi.org/10.1007/s11746-006-0945-0

Shi, Y. D., Jia, L., Li, X., Ma, J. Z., Liu, F., \& Shen, T. B. (2010). Studies on the Spectrum of Tea Seed Oily Properties. Spectroscopy and Spectral Analysis, 30, 2504-2507.

Tarantilis, P. A., Troianou, V. E., Pappas, C. S., Kotseridis, Y. S., \& Polissiou, M. G. (2008). Differentiation of Greek Red Wines on the Basis of Grape Variety Using Attenuated Total Reflectance Fourier Transform Infrared Spectroscopy. Food Chemistry, 111, 192-196. http://dx.doi.org/10.1016/j.foodchem.2008.03.020

Ushikubo, T., Iizuka, T., Hattori, H., \& Tanabe, K. (1993). Preparation of Highly Acidic Hydrated Niobium Oxide. Catalysis Today, 16, 291-295. http://dx.doi.org/10.1016/0920-5861(93)80068-C

Wei, C. C., Yen, P. L., Chang, S. T., Cheng, P. L., Lo, Y. C., \& Liao, V. H. C. (2016). Antioxidative Activities of Both Oleic acid and Camellia tenuifolia Seed Oil Are Regulated by the Transcription Factor DAF-16/FOXO in Caenorhabditis elegans. PLoS ONE, 11, e0157195. http://dx.doi.org/10.1371/journal.pone.0157195

Wei, C. L., Chen, F. Q., Zhang, H. H., \& Zhan, X. L. (2004). Hydrolysis of Glucose Solutions over Niobic Acid as Solid Acid Catalyst. Industrial Catalysis, 12, 46-49.

Woznica, Z., Nalewaja, J. D., Messersmith, C. G., \& Milkowski, P. (2003). Quinclorac Efficacy as Affected by Adjuvants and Spray Carrier Water. Weed Technology, 17, 582-588. http://dx.doi.org/10.1614/0890-037X(2003)017[0582:QEAABA]2.0.CO;2

Xing, R., Subrahmanyam, A. V., Olcay, H., Qi, W., van Walsum, G. P., Pendse, H. et al. (2010). Production of Jet and Diesel Fuel Range Alkanes from Waste Hemicellulose-Derived Aqueous Solutions. Green Chemistry, 12, 1933-1946. http://dx.doi.org/10.1039/c0gc00263a 
Yang, F., Liu, Q., Bai, X., \& Du, Y. (2011). Conversion of Biomass into 5-Hydroxymethylfurfural Using Solid Acid Catalyst. Bioresource Technology, 102, 3424-3429. http://dx.doi.org/10.1016/j.biortech.2010.10.023

Yang, H., Huang, L., Liu, S., Zhao, J., Hou, M., \& Xu, W. (2015). Investigation of Technology and Mechanism of Removing Ash from Camellia oleifera Shell Charcoal Material. Journal of Functional Materials, 46, 18061-18064.

Ye, Y., Li, Y., \& Fang, F. (2015). Cost Effective Isolation of Bioactive Compounds from a Discarded Bioresource Defatted Seeds of Camellia oleifera. BioResources, 10, 1060-1072.

Zhang, D. Q., Guo, L. L., Zhu, Q. D., Peng, W. X., Liu, Q. M., Zeng, S. Z. et al. (2009). Analysis of Value-Added Resource Recovery of Wasted Branchlet and Nutshell of Camellia oleifera by GC/MS. 3rd International Conference on Bioinformatics and Biomedical Engineering (ICBBE) (pp. 1-4). IEEE. http://dx.doi.org/10.1109/icbbe.2009.5162361

Zhang, D., Stack, L., Zhang, R., Yu, J., Xie, B., Chen, Y. et al. (2008) Tea oil Camellia-Eastern "Olive" for the World. In D. Zhang, J.-M. Lee, \& R. Tao (Eds.), International Symposium on Asian Plants with Unique Horticultural Potential (IHC) (pp. 43-48). Leuven: ISHS.

Zhang, D., Xue, Y., Zhong, C., Xu, R., \& Zhu, L. (2014). The Analysis and Comparison of Characteristic Components of Oil-Tea Camellia Seed Oil and Tea Camellia Seed Oil. Journal of the Chinese Cereals and Oils Association, 29, 69-72.

Zhang, L. L., Wang, Y.-M., Wu, D.-M., Xu, M., \& Chen, J.-H. (2010). Comparisons of Antioxidant Activity and Total Phenolics of Camellia oleifera Abel Fruit Hull from Different Regions of China. Journal of Medicinal Plants Research, 4, 1407-1141.

Zhou, Q. F., Jia, X. J., Li, Q. Q., Yang, R. W., Zhang, L., Zhou, Y. H. et al. (2014). Antioxidant and Antimicrobial Activities of Camellia oleifera Seed Oils. Journal of Applied Biological Chemistry, 57, 123-129. http://dx.doi.org/10.3839/jabc.2014.018

Zong, J., Wang, R., Bao, G., Ling, T., Zhang, L., Zhang, X. et al. (2015). Novel Triterpenoid Saponins from Residual Seed Cake of Camellia oleifera Abel. Show Anti-Proliferative Activity against Tumor Cells. Fitoterapia, 104, 7-13. http://dx.doi.org/10.1016/j.fitote.2015.05.001

\section{Submit or recommend next manuscript to SCIRP and we will provide best service for you:}

Accepting pre-submission inquiries through Email, Facebook, LinkedIn, Twitter, etc. A wide selection of journals (inclusive of 9 subjects, more than 200 journals)

Providing 24-hour high-quality service

User-friendly online submission system

Fair and swift peer-review system

Efficient typesetting and proofreading procedure

Display of the result of downloads and visits, as well as the number of cited articles

Maximum dissemination of your research work

Submit your manuscript at: http://papersubmission.scirp.org/

Or contact ojf@scirp.org 